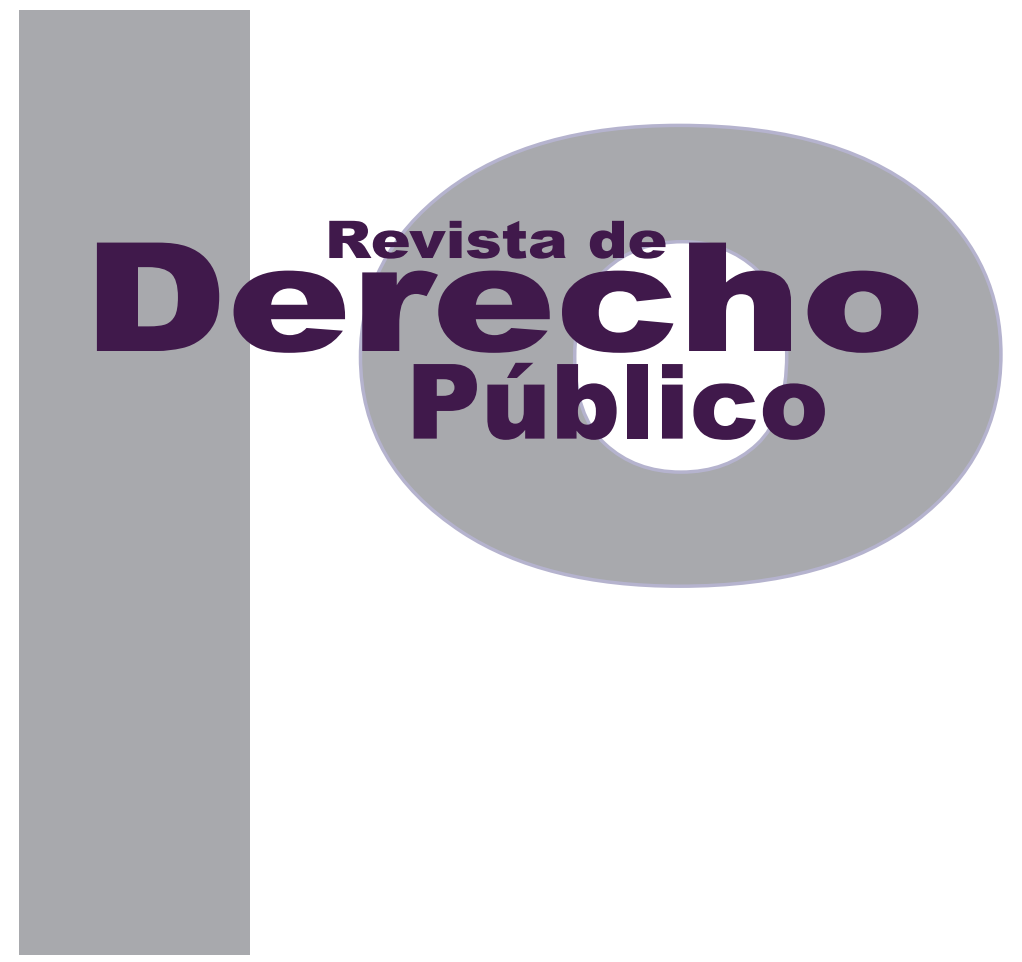

\title{
LA CARGA DE LA PRUEBA EN EL PROCESO PENAL ACUSATORIO EN COLOMBIA: DISYUNTIVA DE APLICACIÓN EN LA JURISPRUDENCIA DE LAS ALTAS CORTES
}

KATHERINE MÜLLER RUEDA

Artículo de investigación científica y tecnológica

Universidad de los Andes

Facultad de Derecho

Revista de Derecho Público N. ${ }^{\circ} 32$

Enero - Junio de 2014. ISSN 1909-7778 


\title{
La carga de la prueba en el proceso penal acusatorio en Colombia: disyuntiva de aplicación en la jurisprudencia de las altas Cortes
}

\section{Resumen}

El presente artículo señala la disparidad de criterios generada al interior de la Corte Constitucional y la Corte Suprema de Justicia, en relación con la utilización de las teorías de la carga dinámica de la prueba en el proceso penal colombiano con tendencia acusatoria, puesto en vigencia mediante la Ley 906 de 2004. Este estudio constituye un análisis normativo, doctrinal y jurisprudencial con enfoque cualitativo de carácter jurídico básico, con el cual se obtiene como resultado que la ausencia de unificación de criterios en las altas Cortes ha permitido la aplicación de la distribución de la carga de la prueba de manera arbitraria, en contra de la prohibición estipulada en el inciso $3^{\circ}$ del artículo $7^{\circ}$ del Código de Procedimiento Penal (C. P. P.).

Palabras clave: Carga de la prueba, debido proceso, sistema penal adversarial, teoría de la carga dinámica de la prueba.

\section{Burden of proof in the adversarial criminal trial in Colombia: Implementation dilemma in the jurisprudence of the high Courts}

\begin{abstract}
This article explains the disparity of criteria generated within the Constitutional Court and the Supreme Court of Justice concerning to the use of the theories of the dynamic burden of proof in the Colombian criminal accusatory tendency process, enactment by Act 906 of 2004. This study was conducted through a normative, doctrinal and jurisprudential analysis with a basic legal qualitative approach. Results determined the absence of unifying criteria in the High Courts allowing the application of the distribution of the burden of proof arbitrarily, contrary to the prohibition in clause 3 article 7 of the Code of Criminal Procedure.
\end{abstract}

Keywords: Burden of proof, adversarial penal system, dynamic burden of proof theory, due process.

\section{A carga da prova no processo penal acusatório na Colômbia: disjuntiva de aplicação na jurisprudência das altas Cortes}

\section{Resumo}

O presente artigo mostra a disparidade de critérios gerada no interior da Corte Constitucional e da Corte Suprema de Justiça, em relação com a utilização das teorias da carga dinâmica da prova no processo penal colombiano com tendência acusatória, posto em vigência mediante a Lei 906 de 2004. Este estudo constitui uma análise normativa, doutrinal e jurisprudencial com enfoque qualitativo de caráter jurídico básico, com o qual se obtém como resultado que a ausência de unificação de critérios nas altas Cortes tem permitido a aplicação da distribuição da carga da prova de maneira arbitrária, contra a proibição estipulada no inciso $3^{\circ}$ do artigo $7^{\circ}$ do Código de Procedimento Penal (C. P. P.). Palavras-chave: Carga da prova, devido processo, sistema penal adversarial, teoria da carga dinâmica da prova. 


\section{SUMARIO}

Introducción - I. MARCO TEÓRICO METODOLOGÍA - A. Aspectos conceptuales sobre la carga de la prueba - 1. Teoría sobre la distribución de la carga de la prueba - 1.1.Teoría de la naturaleza constitutiva, extintiva o modificativa de los hechos - 1.2. Teoría que impone a cada parte la carga de probar el supuesto de hecho de las normas cuya aplicación solicita - 1.3. Teoría que se funda en la dificultad para probar el hecho - B. La carga de la prueba en el derecho penal - 1 . Aspectos normativos de la carga de la prueba penal - 2. La carga de la prueba penal según la doctrina - II. RESULTADOS DE LA INVESTIGACIÓN - A. Evidencia jurisprudencial paradigmática - 1. Carga de la prueba en el delito de acceso carnal violento - 2. La carga de la prueba y el principio de presunción de inocencia - 3. Tendencias de aplicación de la carga dinámica - III CONCLUSIONES - Bibliografía. 


\title{
La carga de la prueba en el proceso penal acusatorio en Colombia: disyuntiva de aplicación en la jurisprudencia de las altas Cortes $^{1}$
}

\author{
Katherine Müller Rueda²
}

\section{Introducción}

La Ley 906 de 2004 introdujo el sistema penal con tendencia acusatoria en Colombia, y a partir de este se dejaron de lado instituciones jurídicas que venían rigiendo bajo el amparo de la Ley 600 de 2000, como fueron el principio de investigación integral y la permanencia de la prueba, entre otras.

Frente a las nuevas dinámicas planteadas por el sistema adversarial, el manejo de la prueba es una temática que adquiere mayor transcendencia en virtud del principio de inmediación, por medio del cual solo podrá considerarse prueba

1 Cómo citar este artículo: Müller Rueda, K. (Junio, 2014). La carga de la prueba en el proceso penal acusatorio en Colombia: disyuntiva de aplicación en la jurisprudencia de las altas Cortes. Revista de Derecho Público, 32

Ponencia finalista del XIV Concurso Internacional de Estudiantes, realizado en el marco del XXXIV Congreso Colombiano de Derecho Procesal (2013), organizado por el Instituto Colombiano de Derecho Procesal.

Investigadora del Centro de Investigaciones Jurídicas y Sociojurídicas de la Universidad Libre Seccional Socorro. Correo: katherine.muller. rueda@gmail.com aquella que ha sido practicada con la intervención del juez y ha estado sujeta a la contradicción de las partes; de manera que resolver la pregunta ¿a quién le corresponde probar qué? es una de las cuestiones más importantes en la actualidad jurídica.

La carga de la prueba en el derecho penal ha sido un aspecto ampliamente debatido en la doctrina, y las opiniones respecto de la posibilidad de implementar la teoría de la carga dinámica se hallan divididas. Mientras algunos la defienden por salvaguardar postulados como la verdad y la justicia material, otros la rechazan por amenazar otros tantos principios como la presunción de inocencia e in dubio pro reo. Esta problemática plantea las siguientes preguntas: ¿se presenta un panorama similar en la jurisprudencia?, ¿existe unificación de criterios en la Corte Constitucional y la Corte Suprema de Justicia sobre la aplicación de la carga dinámica de la prueba en el sistema penal acusatorio colombiano? 
El presente constituye un artículo de investigación científica estructurado de la siguiente manera: en primera instancia se estudia la fundamentación teórica sobre la carga de la prueba en el derecho procesal colombiano. Una vez establecidas estas razones se analizan los aspectos normativos, doctrinales y jurisprudenciales sobre la aplicación del onus probandi en el derecho procesal penal. Finalmente, a partir de la evidencia jurisprudencial analizada, se exponen casos paradigmáticos en donde los criterios aplicados por las altas Cortes (Corte Constitucional y Corte Suprema de Justicia) han entrado en colisión generando un problema de inseguridad jurídica.

\section{MARCO TEÓRICO}

\section{A. Aspectos conceptuales sobre la carga de la prueba}

“Toda persona tiene derecho a conseguir la prueba que le permita demostrar la bondad de su pretensión" (Parra, 2011). En estos términos deja sentado Jairo Parra Quijano el derecho que tienen los sujetos procesales a la prueba; ciertamente, no se ha podido definir de mejor manera lo que, en palabras castizas, constituye el fundamento esencial de la carga de la prueba en el ordenamiento procesal.

Desde una perspectiva general, la carga de la prueba ha sido entendida con una doble connotación. Por un lado, constituye una carga procesal en la medida en que le asigna a las partes una regla de conducta que deberán observar, con la finalidad de establecer los hechos que fundan el derecho que reclaman en el proceso, sean ellos pretensiones o excepciones; por otro lado, implica una regla de juicio para el juez, por cuanto le indica en qué sentido deberá emitir su fallo una vez se concluya que el acervo probatorio es insuficiente, bien porque el sujeto sobre quien recae la carga de la prueba la ha allegado de manera imperfecta o defectuosa, bien porque se carece de ella (Azula, 2008).

En este sentido, la regla de la carga de la prueba es de aplicación subsidiaria, puesto que establece las consecuencias adversas para la parte producto de su inactividad probatoria, así "la teoría de la carga de la prueba es la teoría de las consecuencias de la falta de prueba" (González, 2011). La importancia de ella reside, entonces, en la facultad que tiene el juez para proferir una decisión de fondo, favorable, en el caso en que el sujeto procesal haya satisfecho la carga de probar el hecho que afirmaba; desfavorable, en el caso de no haber satisfecho tal requerimiento con fundamento en el sucedáneo de prueba y siempre eliminando la posibilidad de sentencias inhibitorias o de producción del non liquet romano. Así las cosas, la carga de la prueba será siempre, como se ha señalado, una facultad y no una obligación, dado que las partes están en la libertad de librarse de ella, aun cuando de no hacerlo tengan que soportar las consecuencias jurídicas adversas. 


\section{Teoría sobre la distribución de la carga de la prueba}

El tema de la carga de la prueba ha suscitado gran interés en el mundo procesal, precisamente por la importancia que guarda en relación con el sentido del fallo que por su aplicación pueda llegar a proferirse. En efecto, han sido considerables las disputas y teorías que se han generado respecto a la aplicación de este instituto jurídico. Azula (2008) plantea tres tendencias:

\subsection{Teoría de la naturaleza constitutiva, extintiva o modificativa de los hechos}

Esta teoría fue inicialmente acogida por el Código civil de don Andrés Bello y después incorporada en el Código civil colombiano mediante el artículo 1757. Según ella, le correspondía "probar la obligación o su extinción al que alega aquella o esta", en otras palabras, sobre el demandante o demandado recaía la carga de la prueba tanto de las obligaciones como de su extinción, según fueran sus intereses dentro del respectivo proceso; sin embargo, la carga de la prueba se limitaba única y exclusivamente a las obligaciones, excluyéndose los derechos reales.

\subsection{Teoría que impone a cada parte la carga de probar el supuesto de hecho de las normas cuya aplicación solicita}

Una segunda teoría es la utilizada en Colombia por mandato expreso del artículo 177 inc. $1^{\circ}$ del Código de Procedimiento Civil (Decreto 1400 de 1970), por medio del cual perdió eficacia la dis- posición contenida en el ordenamiento sustancial del artículo 1757 del Código civil. Esta teoría atribuyó a cada parte la carga de la prueba en relación con los hechos controvertidos que debería demostrar, para que el juez pudiese proceder a la aplicación de las normas que invocara. Aquí se daba amplia aplicación al principio actor incumbit probatio, según el cual al actor le incumbe la prueba.

\subsection{Teoría que se funda en la dificultad para probar el hecho}

Finalmente, se consideró la existencia de una tercera y actual tendencia, basada en la movilidad de la carga de la prueba entre las partes según la dificultad de acceder a ella. Esta tendencia tuvo asidero en los aportes realizados por Bentham (1971) y Carnelutti (1944), precursores de las llamadas teorías utilitarista y teleológica respectivamente, quienes atribuyeron la carga a la parte que se hallara en mejores condiciones de lograr la prueba.

Precisamente, la insuficiencia de la doctrina precedente hizo que los juristas entendieran que la carga probatoria no estaba unida exclusivamente al rol de actor o demandante, pues con el tiempo "se dieron cuenta de que se presentaban situaciones donde la parte que negaba tenía a su alcance fácil prueba y la ocultaba de mala fe, mientras que estaba lejos de las posibilidades de la otra el poder aportar elementos de convicción" (Peyrano, 1997), lo que hizo que se permitiera la inversión de las cargas de la prueba en situaciones especiales en las que se presentaba la dificultad de acceder a ella. 
Esta teoría ha sido denominada, en la actualidad, como carga dinámica de la prueba, y consiste en que "el deber de probar un determinado hecho o circunstancia se impone a la parte que se encuentra en mejores condiciones de hacerlo, aun cuando no lo haya alegado o invocado" (Azula, 2008).

En relación con esta tendencia, el nuevo Código General del Proceso (Ley 1564 de 2012) mantuvo en el artículo 167 inc. $1^{\circ}$, en principio, la disposición contenida en el artículo 177 inc. $1^{\circ}$ del Código de Procedimiento Civil, estableciéndola además como regla general. No obstante, consagró de manera expresa la carga dinámica de la prueba, como excepción, si según las particulares condiciones del caso la parte en quien no recae la carga de ella se halla en una situación más favorable para aportar la evidencia o establecer el hecho controvertido.

Así las cosas, nuestro ordenamiento, desde una perspectiva general, ha abogado por la aplicación de la teoría de las cargas dinámicas de la prueba, principalmente, por considerar que por medio de ella se puede llegar a resultados que consulten los principios constitucionales, a través del logro de la verdad sustancial y la justicia material de acuerdo con cada situación particular. Esto con el fin de permitir la inversión de la carga de probar, por la dificultad de obtención de un determinado medio de prueba y en atención al deber de colaboración y el principio de solidaridad.

Sin embargo, en lo que atañe al manejo de este instituto jurídico en el derecho penal, las opiniones se encuentran divididas.

\section{B. La carga de la prueba en el derecho penal}

\section{Aspectos normativos de la carga de la prueba penal}

Desde el punto de vista constitucional, la teoría de la carga de la prueba en el derecho penal halla fundamento, principalmente, en el debido proceso, por cuanto su razón de ser es la de dar a los juzgadores y a las partes procesales unos criterios claros para resolver los problemas de valoración probatoria que puedan plantearse en los casos de inexistencia de pruebas o dudas razonables sobre las pruebas practicadas (Climent, 1999).

El debido proceso se erige, entonces, como la garantía por excelencia con que cuentan todas las personas en un Estado social de derecho, de ser juzgadas conforme a las leyes preexistentes y con observancia irrestricta de las formalidades propias de cada juicio (art. 29 Const. Pol.); su finalidad será la obtención de una decisión válida. Su principal característica estriba en el deber de la actividad judicial de propender por el respeto de la dignidad humana como núcleo esencial del Estado social y democrático de derecho, lo que se traduce en que tanto la investigación como el juicio penal no justifiquen al Estado en buscar la verdad a como dé lugar (González, 2011). Lo anterior implica que, por conducto del debido proceso, ningún funcionario judicial podrá pretermitir etapas procesales o requisitos previamente establecidos en la ley, so pretexto de lograr la verdad real. 
Este postulado básico del ordenamiento jurídico colombiano, que se encuentra consagrado constitucionalmente en el artículo 29, se descompone, a su vez, en diversas garantías que conllevan una recta y cumplida administración de justicia, como son, el derecho de defensa, el derecho de contradicción, el principio de legalidad, de seguridad jurídica, la presunción de inocencia y el in dubio pro reo, entre otras.

El derecho de defensa constituye uno de los componentes esenciales del debido proceso, al consistir en "el poder de voluntad de controvertir las pretensiones, pruebas y argumentos de la contraparte o del Estado, según sea el caso, solicitar y allegar pruebas, formular e interponer recursos, entre otras actuaciones" (Corte Constitucional de Colombia. Sent. C-152, 2004). En el marco del derecho penal, el derecho a una defensa técnica, es decir, aquella que es ejercida por un especialista del derecho, se halla integrado en la Carta Política en virtud del bloque de constitucionalidad (art. 93), específicamente en el Pacto Internacional de Derechos Civiles y Políticos, incorporado al derecho interno mediante la Ley 74 de 1968, artículo $14^{3}$ y en la Convención Americana de Derechos Humanos, aprobada mediante la Ley 16 de 1972, artículo $8^{\circ} .4$

3 3. "Durante el proceso, toda persona acusada de un delito tendrá derecho, en plena igualdad, a las siguientes garantías mínimas: (...) d) A hallarse presente en el proceso y a defenderse personalmente o ser asistida por un defensor de su elección; a ser informada, si no tuviera defensor, del derecho que le asiste a tenerlo, $y$, siempre que el interés de la justicia lo exija, a que se le nombre defensor de oficio, gratuitamente, si careciere de medios suficientes para pagarlo; e) A interrogar o hacer interrogar a los testigos de cargo y a obtener la comparecencia de los testigos de descargo y que estos sean interrogados en las mismas condiciones que los testigos de cargo".

4 "8.2. Toda persona inculpada de delito tiene derecho a que se presuma su inocencia mientras no se establezca legalmente su culpabilidad.
Con relación a los preceptos anteriormente señalados, la Corte Constitucional en recientes pronunciamientos ha señalado la posibilidad del desarrollo de una defensa silente en materia penal como estrategia defensiva. Así, mediante la sentencia C-069 de 10 de febrero de 2009 expresó,

La validez del silencio como estrategia de defensa se explica si se tiene en cuenta que, en virtud del principio de presunción de inocencia, es el Estado quien debe probar no sólo la ocurrencia de un hecho punible sino la responsabilidad del acusado. Así, en ciertas ocasiones es plausible apelar al silencio, cuando este responde a una táctica previamente ponderada y cuidadosamente examinada por el defensor, más no cuando se refleja como fruto del descuido o la desidia del abogado en la gestión de los intereses de su cliente, lo que desde luego deberá ser examinado en cada caso, pues en este último evento el silencio conlleva la afectación de una garantía de orden ius-fundamental.

Así, la carga de la prueba, radicada en cabeza del Estado, le otorga a la defensa la posibilidad de comportarse de manera pasiva, con fundamento en la presunción de inocencia que durante el desarrollo del juicio ostenta el procesado; no obstante, esta plausible estrategia defensiva no es óbice para que se desentienda de asumir un rol dinámico y activo frente a la protección de los intereses del acusado durante todas las etapas procesales, conducta que daría lugar a

Durante el proceso, toda persona tiene derecho, en plena igualdad, a las siguientes garantías mínimas: derecho del inculpado de defenderse personalmente o de ser asistido por un defensor de su elección y de comunicarse libre y privadamente con su defensor; (...) e) derecho irrenunciable de ser asistido por un defensor 
la nulidad por falta de defensa técnica y a las consecuentes sanciones disciplinarias por su incumplimiento de los deberes como abogado.

En igual sentido, el C. P. P., en relación con la carga de la prueba, ha sido enfático al afirmar que es el órgano de persecución penal el único a quien le corresponde soportarla. Lo anterior halla cimiento a lo largo de todo el estatuto procesal punitivo, al consagrar institutos como la presunción de inocencia (inc. $4^{\circ}$ art. 29 Const. Pol. y $7^{\circ}$ C. P. P.) y el in dubio pro reo (art. $7^{\circ}$ C. P. P.) los cuales le imponen el deber a la Fiscalía General de la Nación, como órgano que ostenta la acción penal, de presentar todos los elementos materiales probatorios y evidencias físicas necesarias para lograr una sentencia condenatoria; a falta de ello, será el juez quien determine proferir fallo absolutorio en caso que no se acredite prueba de la existencia del hecho punible o de la responsabilidad del procesado, o resolver a favor del reo cuando la actividad probatoria encaminada a probar los hechos constitutivos de la infracción y las pruebas orientadas a desvirtuarlos generen 'duda razonable' en el juzgador.

En efecto, el artículo $7^{\circ}$ del C. P. P. prohíbe de manera expresa la posibilidad de inversión de la carga probatoria que recae sobre la Fiscalía, y le otorga a la defensa la posibilidad de asumir una actitud pasiva en el transcurso del proceso, al cabo del cual, si el órgano de persecución no logra demostrar la configuración del ilícito se proferirá sentencia absolutoria. En estos términos, el C. P. P. deja sentado el rol de la defensa, pues con fundamento en artículos como el 125 que establece la posibilidad de "no ser obligada a presentar pruebas de descargo o contraprueba, ni a intervenir activamente durante el juicio oral", el 371 que consagra la facultad para presentar o no teoría del caso en desarrollo del juicio oral y el 443 que le atribuye la posibilidad 'si lo considera pertinente' para presentar los alegatos de conclusión, no existe imposición alguna que le obligue a asumir activamente funciones probatorias.

La finalidad de la prueba en el proceso penal será, entonces, la de llevar al juez el conocimiento, más allá de duda razonable, de los hechos y circunstancias materia del juicio y los de responsabilidad penal del acusado (art. 372 ibídem). En ese sentido, el juez deberá, para condenar, tener un conocimiento más allá de toda duda acerca de la responsabilidad o culpabilidad del acusado (art. 381), de tal manera que de no lograrse este cometido la defensa no tendría por qué entrar a desempeñar actividades de contradicción o prueba, lo que evidencia la tendencia del C. P. P. de proteger a toda costa las garantías del procesado.

En este aspecto es importante advertir las reformas que, en cuanto a la práctica de pruebas, se podrían eventualmente poner en vigor, en virtud del proyecto de Ley 126 de 2013, el cual le otorga la posibilidad a la víctima de solicitar la práctica de pruebas y de llevar a efectos el contrainterrogatorio o el interrogatorio, cuando la Fiscalía le hubiese delegado tal función, lo que implicaría sin lugar a duda la radicación de la carga de la prueba en la víctima. 


\section{La carga de la prueba penal según la doctrina}

El manejo de la carga de la prueba en el derecho penal ha sido una situación de controversia en la doctrina. Inclusive, existen teóricos que han considerado la inaplicación de la noción de carga de la prueba al interior del proceso penal. Un exponente de esta posición es Gian Antonio Micheli, quien considera que el concepto de carga probatoria no es aplicable en el derecho penal pues ni el juez, ni el Ministerio Público (órgano de acusación en el sistema italiano) tienen el deber de observar un determinado comportamiento con el fin de impedir las consecuencias adversas que esto podría generar. En palabras del autor,

la carga no tiene la eficacia de estímulo de la actividad de las partes, puesto que no puede decirse que el Ministerio Público sea titular de un interés interno en antagonismo con el imputado; creo, en efecto, que no se puede decir nunca que el órgano de la acusación pública resulta vencido, porque el interés de la sociedad está en el castigo del culpable y en la represión del delito precisamente en cuanto exista un delito y, por consiguiente, un culpable (Micheli, 1961).

En igual sentido, Azula (2008) aboga por la inexistencia del concepto de carga probatoria en materia penal, puesto que considera que esta "como regla de juicio, que le determina al juzgador fallar en contra de la parte sobre quien gravita, tampoco tiene aplicación en el campo penal, porque en este no hay distribución alguna y el criterio a seguir se rige por el principio conocido como in dubio pro reo". Así las cosas, tampoco el sindicado tiene carga alguna para establecer que no es autor del delito o los eximentes de responsabilidad que se configuren a su favor, puesto que de conformidad con el estatuto procesal le corresponde al Estado desvirtuar la presunción de inocencia que este posee.

Sin embargo, la tendencia que impera en la actualidad es la de permitir la aplicación de la teoría de la carga de la prueba en el derecho penal, tal como lo han sostenido Tirado (2006), González (2011), Parra (2011), Pulecio (2012b) y Cruz (2005), entre otros, quienes consecuentemente con el nuevo sistema procesal penal implementado en Colombia, en vigencia de la Ley 906 de 2004, han considerado radicar la carga probatoria en el órgano de persecución penal. Inclusive, algunos autores han propugnado por la implementación de la carga de la prueba en toda clase de sistemas procesales, sean estos inquisitivos, mixtos o dispositivos; en este entendido, "la institución de la carga de la prueba tiene lugar en todo procedimiento judicial en el cual sea necesario aplicar normas jurídicas abstractas a una situación de hecho concreta, independientemente que domine el principio inquisitivo o, por el contrario, el dispositivo" (Rosenberg, 1955).

En principio, existe consenso en la doctrina colombiana sobre la implementación de la teoría de la carga de la prueba en el derecho penal, aun cuando las discusiones en torno a la distribución de esta no han corrido con la misma suerte. Pese a que la gran mayoría de los autores han asignado la carga de la prueba al órga- 
no de persecución penal, esto es, la Fiscalía, de conformidad con lo establecido en el artículo $7^{\circ}$ del estatuto procesal penal existen juristas que promueven una transformación de esta carga estática en favor de una inversión que recaiga sobre la defensa, cuando de un sistema penal adversarial se trata.

En efecto, Devis (2012), partidario de la inversión de la carga de la prueba en el derecho penal, ha sostenido un leve desplazamiento de esta hacia el procesado, pues es este quien tiene interés en que ciertas circunstancias como los hechos exculpativos de su responsabilidad sean demostrados, motivo por el cual debe colaborar con la práctica de los medios probatorios necesarios para que estos se declaren probados. En este entendido afirma: “la regla de la carga de la prueba tiene cierta relativa aplicación a cargo del procesado; porque sufre las consecuencias adversas de la falta de esas pruebas, si el hecho ilícito y su autoría se encuentran plenamente demostrados" (p. 214).

Por su parte, González (2011), comentando la posibilidad de implementar la teoría de las cargas dinámicas de la prueba en virtud de un sistema penal adversarial como el acogido en nuestro ordenamiento en el Acto Legislativo 03 de 2002 y desarrollado por la Ley 906 de 2004 sostiene,

el nuevo modelo acusatorio es un sistema de partes, según el cual el imputado ya no es un sujeto pasivo en el proceso, como lo era bajo el modelo inquisitivo, sino que demanda su participación activa, incluso desde antes de la formulación de la imputación de los cargos. Por lo que sin considerar una inversión de la presunción de inocencia, las cargas procesales se distribuyen entre la Fiscalía y el investigado, imputado o procesado a quien le corresponde aportar elementos de juicio que permitan confrontar los alegatos del acusador, e inclusive los aportados por la víctima a quien también se le permite la posibilidad de enfrentar al imputado (p. 233).

Igualmente, Tirado (2006) manifiesta la necesidad de distribuir las cargas probatorias entre el ente acusador y la defensa a fin de lograr la justicia material, todo ello respetando las garantías fundamentales de quien es sometido a juicio; así, afirma sin dubitación alguna

esta concepción encuentra mayor aceptación con el advenimiento del proceso penal acusatorio de que trata la Ley 906 de 2004 porque ahora sí se busca el equilibrio entre el interés del Estado, mediante la Fiscalía, y el interés del indiciado, imputado o acusado, quienes como adversarios, y con la prohibición para el juez de decretar pruebas de oficio, buscarán sus propios resultados, aunque el interés de aquélla [que tampoco puede desconocer la realidad de lo desfavorable a su contraparte], derive en defensa de un bien mayor, concerniente a la consecución, en lo posible, de la identidad de la verdad y la justicia (p. 520).

Así las cosas, pese a la prohibición expresa consagrada en el artículo $7^{\circ}$ del actual C. P. P., según la cual es inadmisible la inversión de la carga probatoria que reposa en el órgano de persecución, se analizan a diversos autores que acogen la tendencia de la inversión de la carga 
para que esta corra a cargo del procesado, todo ello como consecuencia de un sistema de partes en el que los marcados intereses se enfrentan con el fin de permitir el logro de principios constitucionales como la justicia material y la verdad sustancial.

No obstante lo anterior, esta tendencia doctrinal tiene fuertes contradictores, entre ellos, Jairo Parra Quijano, quien al respecto sostiene, "transportar al proceso penal la noción de cargas dinámicas contradice políticamente la presunción de inocencia, es un mensaje no conveniente" (Parra, 2011), argumento con el cual deja fuera de las fuerzas del proceso penal la actuación de cualquier carácter dinamizador en cuestión de la carga de la prueba.

Siguiendo los planteamientos esbozados por Parra, en un estudio sobre el instituto jurídico, Sebastián Betancourt considera que la implementación de las cargas dinámicas en el proceso penal conlleva la consecuente violación de principios constitucionales como la defensa material, el debido proceso, el in dubio pro reo y la presunción de inocencia, circunstancia que, desde la óptica del ordenamiento jurídico constitucional y penal colombiano y de las garantías universales, es "inconstitucional y, por ende, inaplicable" (Betancourt, 2010).

\section{METODOLOGÍA}

A partir de una investigación con enfoque cualitativo de carácter jurídico, y con base en el análisis de contenido de las sentencias de la
Corte Constitucional y la Corte Suprema de Justicia (Sala de Casación Penal) proferidas entre 2005 y 2013, se determinó la existencia o no de unidad de criterios sobre la aplicación de la carga dinámica de la prueba en el marco de la Ley 906 de 2004.

Para resolver la pregunta problema propuesta, se realizó en primera instancia una revisión de la literatura doctrinal sobre la carga de la prueba en el sistema penal acusatorio; posteriormente, se abordó el estudio sistemático de las normas jurídicas que regulan el instituto en comento.

Igualmente, para estudiar la jurisprudencia sobre el tema planteado, se consultaron las bases de datos en línea ${ }^{5}$ de las altas Cortes mencionadas, teniendo como palabras claves "carga de la prueba" y "onus probandi". Con los resultados de esta búsqueda se procedió a seleccionar las sentencias proferidas en vigencia de la Ley 906 de 2004, y se descartaron las emitidas en virtud de la Ley 600 de 2000.

Finalmente, se analizaron un total de 57 sentencias, 38 de la Corte Suprema de Justicia, Sala de Casación Penal, y 19 de la Corte Constitucional, de las cuales para efectos de depuración se seleccionaron 7 sentencias que hacían referencia explícita al tema central de estudio: la carga dinámica de la prueba. Dichas sentencias fueron escogidas por ser representativas de las diversas tendencias de aplicación soste-

5 Ver: Corte Constitucional de Colombia. Búsqueda Especializada Índice Temático. Disponible en: http://www.corteconstitucional.gov.co/ relatoria/ y Corte Suprema de Justicia de Colombia. Consulta de providencias. Disponible en: http://190.24.134.69/busquedadoc/. 
nidas al interior de las Cortes y por evidenciar sus ambigüedades.

Las sentencias fueron agrupadas según sus presupuestos fácticos, jurídicos y la razón de la decisión (ratio decidendi), en lo que se denominó evidencia jurisprudencial paradigmática.

\section{RESULTADOS DE INVESTIGACIÓN}

\section{A. Evidencia jurisprudencial paradigmática}

La aplicación de la teoría del onus probandi penal en materia jurisprudencial, a la par con la doctrina, tampoco ha hallado consenso. Las líneas de pensamiento no son claras en cuanto a la procedencia o no de la inversión de la carga de la prueba ni en la Corte Constitucional ni en la Sala de Casación Penal de la Corte Suprema de Justicia. Lo que sí es evidente es que se ha venido desarrollando de manera expresa en la jurisprudencia, en algunos casos, bajo la vigencia del sistema mixto de la Ley 600 de 2000 y ha cobrado mayor vigencia bajo el modelo de tendencia acusatoria de la Ley 906 de 2004 (Pulecio, 2012a).

Así las cosas, se expondrán a continuación tres puntos de derecho paradigmáticos, en los cuales, pese a la similitud de los presupuestos fácticos, la Corte Constitucional y la Corte Suprema de Justicia han fundamentado sus decisiones en criterios que no guardan unanimidad y que hacen inferir una contradicción en sus planteamientos sobre el manejo de la carga dinámica de la prueba en materia penal.
1. Carga de la prueba en el delito de acceso carnal violento

La sentencia de casación de radicado 31.103, proferida el 27 de marzo de 2009 por el magistrado ponente Sigifredo Espinosa Pérez, constituye uno de los casos más controvertidos de aplicación de la carga dinámica de la prueba en materia penal. En esta oportunidad, la Sala analizó una absolución presentada frente a los delitos de acceso carnal violento en concurso con otros tantos de incesto. El caso se centra en el acceso carnal que por vía anal perpetrara, presuntamente, el procesado Julio César Palacio, con amenazas de golpes y arma de fuego sobre su hijo menor, hecho que fue denunciado por la tía de la víctima.

Como consecuencia de dicha denuncia, la Fiscalía imputó al procesado los delitos de acceso carnal violento agravado por transmisión de enfermedad sexual en concurso heterogéneo sucesivo e incesto, siendo declarado penalmente responsable en sentencia de primera instancia, la cual fue apelada por la defensa.

En segunda instancia, el Tribunal Superior de Medellín revocó la sentencia emitida por el a quo, profiriendo, en su lugar, fallo absolutorio con fundamento en el principio de in dubio pro reo al considerar que la defensa, al aportar la historia clínica en donde se establecía que se había practicado prueba de serología que no detectó existencia de enfermedad de transmisión sexual alguna, había logrado generar una duda razonable en el juzgador, duda que la Fiscalía no logró derruir al no aportar prueba confirma- 
toria de la supuesta enfermedad que padecía el acusado, y que, por medio del acceso carnal violento, este pudiese haber transmitido a su menor hijo.

En este entendido, menciona el ad quem "resulta paradójico e indolente que la Fiscalía señalara la obligación para la defensa de 'desvirtuar la presunción de inocencia', pasando por alto que es al ente acusador a quien corresponde la carga de la prueba, tornándose imperativo para el ente estatal pedir la prueba confirmatoria de laboratorio, ya que a la parte defensiva no se le obliga a presentar prueba de descargo" (Corte Suprema de Justicia, sent. 31.103, 2009).

Frente a la sentencia de segunda instancia, la Fiscalía plantea el recurso extraordinario de casación formulando fundamentalmente dos argumentos: por una parte, que el ad quem omitió la valoración de las pruebas testimoniales practicadas al menor, sus tías y su abuela, que demostraban que la víctima había sido contagiada de una enfermedad de transmisión sexual por el procesado, fruto de los vejámenes sexuales que este le generaba; por otra parte, que la prueba de serología allegada al proceso por la defensa, mediante la cual se establecía que no se habían detectado enfermedades venéreas en el procesado, no era concluyente por cuanto, de conformidad con lo dicho por los especialistas en el desarrollo del juicio, esta es una prueba de carácter presuntivo y no confirmatorio, debiendo haber sido confirmada a través de la prueba de FTA absorbido, asunto que debió demostrar la defensa y que nunca hizo.
En este evento, la Corte Suprema de Justicia, con fundamento en la aplicación de la teoría de la carga dinámica de la prueba, determinó que si bien es cierto a la defensa se le permite la adopción de un comportamiento pasivo, posibilidad que deviene de la imposición de la carga de la prueba en cabeza de la Fiscalía, con cimiento en el postulado fundamental de presunción de inocencia e in dubio pro reo, existen claras limitaciones a esta carga en virtud del sistema de connotación adversarial impuesto por la Ley 906 de 2004, que demandan del procesado o su defensor la tarea de desvirtuar las pruebas de la Fiscalía cuando se haya constatado que las mismas son suficientes para determinar la existencia del delito y la participación en este.

En consecuencia, la Corte consideró que la Fiscalía había demostrado sin lugar a duda la responsabilidad penal del acusado por conducto de la veracidad del testimonio del menor, así como por las declaraciones de las tías y la abuela de la presunta víctima, testigos de referencia, quienes acreditaron que tanto el procesado como su esposa habían padecido de sífilis y, a su vez, habían escuchado, por relato del menor agredido, que su padre le había contagiado esta enfermedad por haberlo accedido en diferentes ocasiones. Adicionalmente, la Corte determinó que el requerimiento realizado por el ad quem a la Fiscalía por no haber aportado prueba de FTA absorbido, desconocía el principio de libertad probatoria, por cuanto la ley no exige para ello un medio de prueba en concreto, dado que en vigencia del sistema penal acusatorio no se aplica la tarifa legal de prueba, como otrora lo hiciera la Ley 600 de 2000. 
Aun así, pese a que consideró que en virtud de la libertad probatoria los testimonios de referencia de los familiares de la víctima podían demostrar la existencia de la enfermedad de transmisión sexual tanto en el procesado como en su cónyuge, la Corte no les atribuyó poder suasorio por cuanto encontró que

ante la imprecisión temporal que surge de lo declarado por los familiares del menor y este mismo, en tanto, no se conoce en concreto cuál fue la enfermedad venérea padecida en el pasado por el acusado, ni cómo fue tratada ella o cuáles fueron sus alcances, ese resultado parcial negativo cobra bastante importancia, pues, cuando menos permite albergar la posibilidad, así fuese mínima, de que el contagio no se presentase por consecuencia del vejamen denunciado (Corte Suprema de Justicia, sent. 31.103, 2009) [subrayas añadidas].

razón por la cual procedió a eliminar el agravante respectivo, pero manteniendo todos los demás cargos.

Nótese cómo la Corte maneja una ambigüedad argumentativa al plantear el principio de libertad probatoria, en virtud del cual establece que la prueba testimonial de referencia aportada por la Fiscalía tiene vocación para demostrar la existencia de una enfermedad de transmisión sexual, en tanto que no opina lo mismo respecto del dictamen de serología allegado por la defensa, al cual no le atribuye poder suasorio toda vez que considera que este no es lo suficientemente confirmatorio de la ausencia de la enfermedad, pretendiendo atribuirle mayor convicción a unos testigos de oídas que a una prueba científica que contaba con la vocación suficiente para generar dudas en el juzgador, aun cuando esta fuera tan solo de carácter presuntivo.

Es evidente, en el caso en concreto, la inversión de la carga de la prueba en contra del principio de in dubio pro reo, máxime si se tiene en cuenta que es la misma Corte, al denegar la procedencia del agravante punitivo, la que establece que el resultado negativo que arroja el dictamen de serología albergaba la posibilidad de que "el contagio no se presentase por consecuencia del vejamen denunciado", esto es, del acceso carnal abusivo, de lo que cabe cuestionarse ¿por qué ante la evidente duda no hizo lo propio respecto de los demás cargos formulados?

Por otra parte, mediante la sentencia de casación n. ${ }^{\circ} 31.846$, proferida el $1^{\circ}$ de junio de 2011, al analizar un caso de similares presupuestos fácticos esta misma Corporación parece no solo desconocer el pronunciamiento anterior, sino también contrariarlo. Los hechos se centran en el acceso carnal violento sufrido por un menor de 12 años de edad, presuntamente realizado por el procesado Omar Darío Velásquez Beltrán, acceso con el que supuestamente el menor fue contagiado de blenorragia.

La Fiscalía formuló acusación por el delito de acceso carnal violento, agravado por enfermedad de transmisión sexual. El juzgador de primera instancia profirió sentencia de carácter absolutorio, la cual fue apelada por el órgano de persecución penal, siendo revocada por el Tribunal. Finalmente, la defensa acudió en casación, al considerar que la Fiscalía no había probado 
que el sindicado padeciera la enfermedad que supuestamente había transmitido al menor, en tanto que la defensa sí había aportado historias clínicas de las cuales se infería que ni él ni su pareja hubiesen sufrido de ella, por lo que, a juicio del defensor, no pudo ser el enjuiciado el autor de la conducta punible.

La Corte decidió no casar la sentencia con fundamento en que, según la bacterióloga Blanca Nubia Gaviria Correa, el procesado fácilmente pudo erradicar su enfermedad con la medicación apropiada, presumiendo así su culpabilidad. En el mismo sentido, argumentó que la credibilidad del menor es inobjetable y que, no existiendo prueba en contrario que desvirtúe que la víctima fue contagiada, solo restaba declarar la responsabilidad del procesado.

Sin embargo, pese a la decisión a la que llega la Corte, en ningún momento manifiesta aplicar la teoría de la carga dinámica de la prueba, todo lo contrario, hace un llamado al órgano de persecución, quien "por mandato constitucional y legal tiene la carga de la prueba y el deber de probar su teoría" (Corte Suprema de Justicia, sent. 31.846, 2011), para que actúe activamente, por cuanto una investigación lógica, teniendo conocimiento de la existencia de la enfermedad de transmisión sexual en el menor, le imponía el deber de lograr que tanto sobre el procesado como sobre su pareja se practicaran los dictámenes médicos necesarios para acreditar la existencia de la enfermedad o los restos de sustancias que usualmente se emplean para su cura. Así, como conclusión, la Corte sostiene "lo que no puede admitirse es que el dueño de la investigación y la acusación, el que tiene la carga de la prueba, muestre total pasividad en temas que eran manifiestos, máxime cuando se trata de delitos como el investigado, en donde las más de las veces el asunto se limita a la confrontación de las versiones víctima- acusado" (Corte Suprema de Justicia, sent. 31.846, 2011).

Obsérvese la inconsistencia en la aplicación de la carga de la prueba en los dos casos precedentes, pese a la gran similitud de los hechos que fundan la acción. Ambos parten de la presunta comisión de un delito de acceso carnal violento, con el agravante de enfermedad de transmisión sexual; en los dos la defensa allega al proceso historia clínica en la que se evidencia que ninguno de los procesados ha presentado dicha enfermedad, en tanto que la Fiscalía no aporta prueba que lo confirme; y, finalmente, en los dos pronunciamientos se llega a establecer condena con base en criterios ampliamente disímiles, pues la ratio decidendi que conllevó a la condena impuesta en el primer caso se basó en la inversión de la carga de la prueba, con fundamento en la cual correspondía a la defensa demostrar la ausencia de enfermedad de transmisión sexual del procesado por medio de una prueba de FTA absorbido, mientras que la ratio decidendi que conllevó a la condena impuesta en el segundo caso hizo hincapié en la radicación de la carga de la prueba en cabeza de la Fiscalía como órgano de persecución penal, sin la admisión de inversión de carga probatoria alguna. Igualmente, es de anotar que en el primer caso se dejó de aplicar el agravante punitivo, por cuanto la Corte consideró que la prueba de 
la historia clínica generó duda y en el segundo caso, pese a que también se aportó el mismo elemento, la Corte mantuvo el agravante.

Llama la atención que en ambos casos se arriba a una condena exclusivamente con fundamento en el testimonio del menor, en oposición al del procesado, atribuyéndosele el carácter de ‘inobjetable’ y entrando, por tanto, a cobrar mayor peso la presunción de veracidad que se le concede al testimonio del menor en oposición a la presunción de inocencia que reposa sobre el reo y en contra del acervo probatorio defensivo.

\section{La carga de la prueba y el principio de presunción de inocencia}

En lo que atañe a la Corte Constitucional, tampoco es posible afirmar la unanimidad de criterios en cuanto al manejo de la carga probatoria penal. En este sentido, un aspecto de gran relevancia que ha sido estudiado por este máximo tribunal es el que atañe a la presunción de inocencia y la implementación de las teorías de la carga dinámica de la prueba.

En la sentencia C-069 de 2009, proferida por la magistrada Clara Inés Vargas Hernández, la Corte Constitucional estudió a fondo el derecho a la defensa, la presunción de inocencia y la onus probandi en el marco de un sistema con tendencia acusatoria. En esta oportunidad la Corte determinó que, en vigencia del sistema establecido por la Ley 906 de 2004 correspondía a las partes, esto es, la defensa y la Fiscalía, desempeñar un rol activo. Aquí hizo una importante precisión respecto del papel que debía cumplir la defensa en el marco de un proceso de índole adversarial, aspecto sobre el cual señaló lo siguiente:

el imputado ya no es un sujeto pasivo en el proceso, como lo era bajo el modelo inquisitivo, sino que demanda su participación activa, incluso desde antes de la formulación de la imputación de cargos. Por lo que, sin considerar una inversión de la presunción de inocencia, las cargas procesales se distribuyen entre la Fiscalía y el investigado, imputado o procesado a quien le corresponde aportar elementos de juicio que permitan confrontar los alegatos del acusador, e inclusive los aportados por la víctima a quien también se le permite la posibilidad de enfrentar al imputado (Corte Constitucional, sent. C-069, 2009).

De esta forma, la Corte Constitucional reconoce la posibilidad de radicar en cabeza de la defensa el deber de traer a juicio elementos de prueba que permitan derruir la credibilidad de las pruebas presentadas no solo por su contendiente principal en el proceso, la Fiscalía, sino también las allegadas por la víctima. Igualmente manifiesta el alto tribunal constitucional:

El nuevo sistema impone a la defensa una actitud diligente en la recolección de los elementos de convicción a su alcance, pues ante el decaimiento del deber de recolección de pruebas exculpatorias a cargo de la Fiscalía, fruto de la índole adversativa del proceso penal, la defensa está en el deber de recaudar por cuenta propia el material probatorio de descargo. El nuevo modelo supera de este modo la presencia pasiva del procesado penal, comprometiéndolo con la investigación de lo que le resulte favorable, sin disminuir por ello la plena vigen- 
cia de la presunción de inocencia (sent. C-069, 2009).

Las anteriores consideraciones prácticamente terminan imponiéndole a la defensa la carga probatoria de acreditar todas las circunstancias de no culpabilidad del procesado, con fundamento en el tipo de sistema adoptado por la nueva normatividad penal. No obstante, tres años después este mismo órgano parece recular en sus planteamientos, al abordar el estudio de estos mismos tópicos en la sentencia C-121 de 2012, en donde estableció, de conformidad con el estudio del derecho constitucional comparado, que es a la acusación a quien le corresponde la carga de la prueba acerca de la responsabilidad penal.

En este pronunciamiento, el tribunal constitucional colombiano, siguiendo los planteamientos del Comité de Derechos Humanos, asevera que la carga de la prueba no le corresponde en ningún caso al acusado; así, según los lineamientos jurisprudenciales internacionales,

para establecer la responsabilidad penal del imputado, el estado (sic) debe probar su culpabilidad más allá de toda duda razonable, la presunción de inocencia se relaciona en primer lugar, con el ánimo y actitud del juez que debe conocer de la acusación penal. El juez debe abordar la causa sin prejuicios y bajo ninguna circunstancia debe suponer que el acusado es culpable. Por el contrario, su responsabilidad reside en construir la responsabilidad penal de un imputado a partir de la valoración de los elementos de prueba con los que cuenta (Corte Constitucional, sent. C-121, 2012).
Para concluir su argumentación, la Corte Constitucional señala con contundencia que es en virtud del "principio de presunción de inocencia que el acusado no está obligado a presentar prueba alguna que demuestre su inocencia. Por el contrario, este postulado ordena a las autoridades judiciales competentes la demostración de la culpabilidad del agente" (sent. C-121, 2012), presunción esta que, a criterio de la Corte, acompaña al acusado hasta el momento en que se profiere sentencia de fondo, de manera tal que mientras el órgano de persecución penal no demuestre más allá de duda razonable la culpabilidad del procesado, deberá proferirse sentencia absolutoria.

Así, es evidente cómo la Corte Constitucional, al analizar la aplicación de la teoría de la carga dinámica de la prueba frente al principio de presunción de inocencia en dos sentencias de constitucionalidad, las cuales, se recuerda, son de orden público y de obligatorio acatamiento, resuelve en dos sentidos el problema planteado. Por una parte, reconoce la utilización dinamizadora de la carga probatoria a cargo de la defensa, en la medida en que le impone al procesado el deber de presentar elementos de convicción que demuestren su inocencia. Y, por otra, en reciente sentencia, estima que es precisamente en virtud del principio de presunción de inocencia que el procesado no tiene el deber de presentar prueba de descargo para demostrar su no culpabilidad. 


\section{Tendencias de aplicación de la carga dinámica}

Del análisis jurisprudencial realizado a las sentencias proferidas por la Corte Constitucional y la Corte Suprema de Justicia, Sala de Casación Penal, en el período 2005-2013, se pueden avizorar tres criterios de aplicación de la carga dinámica de la prueba en un sistema de tendencia acusatoria: una implementación de la carga dinámica de la prueba como regla general, una aplicación restringida o restrictiva y, finalmente, la tesis que postula su no aplicación. A continuación se dan a conocer estas tres posturas a partir del análisis de casos concretos.

Mediante la sentencia de casación proferida el 7 de noviembre de 2012 por el magistrado Javier Zapata Ortiz, de radicado 36.578 , la Corte Suprema de Justicia impone el deber de no invertir el onus probandi en un delito de fabricación, tráfico y porte de armas de fuego; los argumentos en los que se basa para proferir tal pronunciamiento consisten en la inexistencia de prueba aportada por la Fiscalía al proceso, que demuestre la comisión de la conducta punible endilgada. En esta oportunidad, la Corte Suprema casa de manera oficiosa la sentencia por considerar que con la decisión proferida por el tribunal superior se atenta de manera flagrante y evidente contra el principio de presunción de inocencia, al exigírsele al acusado presentar la prueba del salvoconducto para desvirtuar la acusación de la Fiscalía.

Como fundamento de su decisión el máximo tribunal de la jurisdicción ordinaria establece que no es posible presumir argumentativamente el elemento de configuración de este tipo penal, cual es el portar el arma sin permiso de autoridad competente, por cuanto es deber del órgano de persecución penal aportar los elementos de prueba indispensables para la declaración de culpabilidad. En este sentido, la Corte manifiesta que exigirle al acusado presentar el permiso de autoridad competente para demostrar su inocencia, vulnera la garantía de presunción de inocencia contenida en el artículo $7^{\circ}$ del estatuto procesal penal, puesto que es a la Fiscalía a quien le corresponde aportar prueba sobre la responsabilidad penal, de manera que permitir la inversión de la carga de la prueba en perjuicio de los intereses del acusado, a consideración de la Corte, violaría la proscripción establecida en el artículo en mención, según la cual en ningún caso podrá invertirse la carga de la prueba que posee el órgano de acusación.

Es evidente que en este caso la Corte Suprema, bajo ningún precepto, acoge la implementación de la teoría de las cargas dinámicas de la prueba en el proceso penal, por expresa prohibición contenida en el inciso tercero del artículo $7^{\circ}$ del estatuto procesal punitivo y por considerar que, de permitir tal inversión, se violarían en consecuencia el principio de presunción de inocencia y la duda probatoria en favor del procesado.

Por otra parte, en sentencia identificada con radicado 33.660, proferida por el magistrado ponente Fernando Alberto Castro Caballero, el 25 de mayo de 2011, se observa cómo la Corte Suprema de Justicia cambia de criterio en cuanto a la implementación de la carga dinámica, puesto 
que, al decidir un delito de homicidio, respecto del cual el procesado asume como estrategia defensiva alegar un caso fortuito, permite la inversión de la carga probatoria en cabeza de la Fiscalía en el entendido que,

la carga de la prueba en el campo penal, como manifestación del principio de presunción de inocencia, y del derecho a la igualdad, no se torna absoluta como para que se avale la actitud pasiva de la parte acusada, pues en situaciones en las que emerge una dificultad en la parte acusadora para probar determinado hecho, pero la parte acusada cuenta con la facilidad de aportar el medio necesario para ello, siempre que beneficie sus intereses, se hace necesario restablecer el equilibrio en procura que la prueba de la circunstancia controvertida sea aportada por la parte que pueda acceder al medio de convicción.

De lo anterior se colige que es en virtud del principio de la carga dinámica de la prueba que a la defensa le corresponde asumir activamente el onus probandi para demostrar los hechos que le interesan, con el fin de obtener una sentencia favorable. Esto en vigencia de un sistema adversarial como el planteado por el nuevo C. P. P., pues como lo sostiene la Corte Suprema de Justicia "el proceso acusatorio exige de la defensa un mayor despliegue investigativo, pues su labor no se limita a esperar que el acusador desvirtúe la presunción de inocencia, sino que asume el rol de rebatir la prueba de cargo de la Fiscalía, no únicamente a partir de argumentos, sino de medios probatorios que cuenten con la idoneidad de desacreditar lo aprobado por su adversario" (sent. 33.660, 2011).
Aquí, la Corte Suprema de Justicia le impone a la defensa el deber de probar los hechos que le beneficien, cambiando así la postura asumida en el caso precedente, en donde partía de la premisa según la cual, cualquier inversión de la carga de la prueba en materia penal implica la violación de la presunción de inocencia, el in dubio pro reo y la carga probatoria en cabeza de la Fiscalía.

En el caso objeto de análisis el máximo tribunal de la jurisdicción ordinaria plantea una posición ecléctica al permitir implementar la carga dinámica de la prueba en materia penal de manera restringida, por atribuir excepcionalmente a la defensa el onus probandi para desvirtuar las pruebas de cargo de la Fiscalía solo en la hipótesis de que estas pruebas de cargo sean suficientes y pertinentes para la demostración de la responsabilidad penal del implicado, en cuyo caso, le corresponde a la defensa aportar elementos de juicio que permitan generar duda respecto de la credibilidad del acervo probatorio del órgano de la acusación.

Finalmente, se evidencia cómo la Corte Suprema de Justicia opta por asumir la implementación de la teoría de la carga dinámica de la prueba como regla general en el derecho penal, mediante la sentencia 31.103, proferida el 27 de marzo de 2009 por el magistrado ponente Sigifredo Espinosa Pérez, anteriormente relacionada. En esta oportunidad, como ya se reseñó, se otorga viabilidad a la teoría objeto de estudio sin restricción alguna, al imponerle a la defensa el deber de aportar la prueba para demostrar la ausencia de enfermedad de transmisión sexual, 
decisión con base en la cual se llega a dejar a cargo del procesado el deber indiscutible de demostrar su inocencia, pese a la presunción que obra a su favor.

\section{CONCLUSIONES}

Como resultado de los análisis jurisprudenciales se puede afirmar que, en la actualidad, no existe un criterio unánime para la aplicación de la teoría de la carga dinámica de la prueba en materia penal, ni en la doctrina, ni en la jurisprudencia de la Corte Constitucional y la Sala de Casación Penal de la Corte Suprema de Justicia, pese a la claridad de lo estipulado en la norma tanto constitucional como legal.

El artículo 29 superior consagra, entre otros, los postulados de presunción de inocencia e in $d u$ bio pro reo. A su vez, el artículo $7^{\circ}$ del C. P. P. establece que toda persona se presume inocente, y debe ser tratada como tal, hasta tanto una decisión judicial en firme no determine su responsabilidad penal, razón por la cual atribuye a la Fiscalía General de la Nación, como órgano de persecución penal, la carga de la prueba sobre los hechos constitutivos del punible, prohibiendo la inversión de la carga probatoria de manera absoluta y sin ninguna posibilidad diferente.

Sin embargo, en la jurisprudencia estudiada se ha evidenciado que las altas Cortes se han apartado de la normatividad vigente para establecer criterios que han permitido la posibilidad de invertir el onus probandi, dando paso a tres tendencias de aplicación de la teoría de la carga dinámica de la prueba: aplicación restringida, aplicación como regla general e inaplicación. Esta disparidad de criterios en la aplicación del onus probandi penal está generando un grave problema de inseguridad jurídica, por cuanto el procesado no tendrá ninguna certeza sobre el criterio que aplicará, en su caso particular, a la hora de decidir su absolución o su condena.

Las altas Cortes han justificado la aplicación de la carga dinámica de la prueba como mecanismo para evitar la impunidad, so pretexto de la búsqueda de una verdad sustancial y una justicia material. Criterio que ha conllevado que, en la práctica, la aplicación de la carga dinámica de la prueba justifique una sentencia de carácter condenatorio, sacrificándose con ello la presunción de inocencia.

Otro de los aspectos que más llama la atención es que en la sentencia definitiva es en donde se está determinando cuándo el juez de conocimiento considera apto aplicar la carga dinámica de la prueba, situación concreta que, en materia de derecho privado, fue objeto de reforma en el nuevo Código General del Proceso.

En virtud del nuevo ordenamiento procesal, se eliminó la dañina posibilidad de considerar en la sentencia la inversión del onus probandi, al asignarle al juez el deber de hacer dicha distribución, no en el fallo definitivo sino en una providencia anterior que le otorgue a la parte perjudicada con la inversión un término suficiente para cumplir con la nueva carga que se le asigna.

Así se erradicó la reprochable situación que, según Ulises Canosa Suárez, "conducía equivoca- 
damente a aplicarle el sucedáneo de prueba a quien no se le había advertido de su compromiso, ni había tenido la oportunidad de alegar al juez que realmente no se encontraba en mejor posición para probar" (Canosa, 2012).

Ahora bien, si determinar en la sentencia la inversión de la carga de la prueba en el ordenamiento privado fue un aspecto duramente criticado que terminó con su modificación, establecer en un fallo definitivo penal la implementación del onus probandi dinámico es aún más reprochable, si se tiene en cuenta que es en esta clase de procesos donde intereses de mayor entidad están en juego.

En suma, se pueden realizar tres afirmaciones con base en la jurisprudencia analizada: la primera de ellas es que la implementación de la teoría de la carga dinámica de la prueba en materia penal ha significado la violación de importantes garantías de rango constitucional y legal; la segunda, que las altas Cortes no están acatando la normatividad vigente al respecto; y la tercera, que los criterios esgrimidos por estas altas corporaciones han entrado en contradicción, siendo apenas evidente que no han atendido sus propios precedentes.

Por las anteriores razones, resulta sumamente importante para la comunidad jurídica resolver esta problemática aprovechando la coyuntura actual de la propuesta de reforma al sistema penal acusatorio, iniciativa impulsada por la Sala Penal de la Corte Suprema de Justicia y la Fiscalía General de la Nación, con el fin de remediar las falencias en la aplicación de institutos del derecho penal.
En consecuencia, fruto de la presente investigación, se recomienda desde el ámbito académico el acatamiento de la sentencia C-121 de 2012 para efectos de aplicación judicial, pues es el faIlo más respetuoso de los derechos y garantías del imputado en un sistema con tendencia acusatoria, en el marco de un Estado social y democrático de derecho, más aún cuando este fallo observa la prohibición contenida en la normatividad procesal penal. Por lo anterior, se postula la no implementación de la teoría de la carga dinámica de la prueba en el proceso penal.

Es la ley la que debe determinar el onus probandi a fin de que las partes tengan muy claro a quién le corresponde probar qué y, en consecuencia, a quién le corresponde asumir los resultados adversos de la falta de prueba. De manera que, si las reglas de juego se están fijando en la jurisprudencia, y es ella la que no tiene establecido un criterio único de aplicación de estas, se está poniendo en manos de la arbitrariedad del juzgador un aspecto fundamental para la vida de una persona como lo es, por ejemplo, su libertad.

Sin embargo, una vez contrastada la hipótesis surge una duda que constituye el punto fundamental de la investigación, y consiste en qué podrían hacer los litigantes frente a aquellas sentencias tanto de la Corte Constitucional como de la Corte Suprema de Justicia que han permitido la aplicación de la teoría de la carga dinámica de la prueba en desmedro de las garantías y derechos fundamentales del procesado. 
Para responder a este interrogante es necesario aclarar que, en la actualidad, se cuenta con tres mecanismos que permitirían corregir los yerros de la aplicación irrestricta de la teoría de la carga dinámica de la prueba por parte de las altas Cortes: el primero, la solicitud de nulidad, cuya eficacia se circunscribe a la actuación diligente en la defensa del derecho al debido proceso, pues deberá llevarse a cabo dentro de los tres días siguientes a la notificación de la sentencia adoptada por la Corte; el segundo, la petición de tutela, cuyo objetivo fundamental es la defensa de los derechos fundamentales y la protección ante las violaciones cometidas por las autoridades públicas; y, finalmente, una vez agotados sin éxito los anteriores mecanismos, la posibilidad de acudir al Sistema Interamericano de Derechos Humanos, en virtud del control de convencionalidad, donde sería la Corte Interamericana de Derechos Humanos la encargada de dirimir el conflicto, previa interpretación de la normatividad internacional.

A manera de conclusión final: en el presente artículo se ha determinado la posición de las Cortes en torno al tema de la carga de la prueba, la cual, se reitera, ha sido ambigua. Ahora bien, el estudio de los motivos que explican este fenómeno supera con creces este trabajo, por lo cual se proponen como planes de investigaciones futuras.
Referencias

Azula, J. (2008). Manual de Derecho Procesal. Pruebas judiciales. ( $3^{\mathrm{a}}$ ed.). Tomo VI. Bogotá: Editorial Temis.

Bentham, J. (1971). Tratado de las pruebas judiciales. Tomo I. Buenos Aires: Ediciones Jurídicas Europa-América.

Betancourt, S. (2010). La carga dinámica de la probatoria y su repercusión en el proceso penal desde las reglas de Mallorca y la teoría del garantismo penal. Revista Ratio Juris, 25-44.

Canosa, U. (2012). Código General del Proceso. Aspectos probatorios. Memorias del XXXIII Congreso Colombiano de Derecho Procesal, 39.

Carnelutti, F. (1944). Sistema de derecho procesal civil. Buenos Aires: Ediciones Jurídicas Europa-América (EJEA).

Climent, C. (1999). La prueba penal (doctrina y jurisprudencia). Valencia: Editorial Tirant Io Blanch.

Congreso de la República de Colombia. (Septiembre 1 de 2004). Ley 906 de 2004. "Por la cual se expide el Código de Procedimiento Penal”. Diario Oficial n. ${ }^{\circ} 45658$.

Congreso de la República. (Octubre 17 de 2013). Proyecto de Ley 126 de 2013. "Por el cual se modifica la Ley 906 de 2004 Código de Procedimiento Penal". Gaceta n. ${ }^{\circ} 840 / 13$. 
Congreso de la República. (Julio 12 de 2012). Ley 1564 de 2012. "Por medio de la cual se expide el Código General del Proceso y se dictan otras disposiciones". Diario Oficial n. ${ }^{\circ}$ 48.489.

Constitución Política de Colombia. Julio 7 de 1991.

Corte Constitucional. Búsqueda Especializada Índice Temático. Disponible en: http://www. corteconstitucional.gov.co/relatoria/.

Corte Constitucional. Sentencia C-152 de 24 de febrero de 2004. M. P.: Jaime Araújo Rentería.

Corte Constitucional. Sentencia C-069 de febrero 10 de 2009. M. P.: Clara Inés Vargas Hernández.

Corte Constitucional. Sentencia C-121 de febrero 22 de 2012. M. P.: Luis Ernesto Vargas Silva.

Corte Suprema de Justicia. Consulta de providencias. Recuperado de http://190.24.134.69/ busquedadoc/.

Corte Suprema de Justicia. Sala de Casación Penal. Sentencia 31.103 de 27 de marzo de 2009. M. P.: Sigifredo Espinoza Pérez.

Corte Suprema de Justicia. Sala de Casación Penal. Sentencia 33.660 de mayo 15 de 2011. M. P.: Fernando Alberto Castro Caballero.
Corte Suprema de Justicia. Sala de Casación Penal. Sentencia 36.578 de noviembre 7 de 2012. M. P.: Javier Zapata Ortiz.

Cruz, L. (2005). Carga de la prueba y exclusión de responsabilidad en el nuevo sistema procesal. Revista Derecho Penal y Criminología, 26(78), 145-170.

Devis, H. (2012). Compendio de derecho procesal. Pruebas judiciales. (11 ${ }^{a}$ ed.). Tomo II. Bogotá: Editorial Temis.

González, A. (2011). La prueba en el Sistema Penal Acusatorio. Bogotá: Leyer.

Micheli, G. A. (1961). La carga de la prueba. Buenos Aires: Ediciones Jurídicas EuropaAmérica.

Parra, J. (2011). Manual de derecho probatorio. (10ª Ed.). Bogotá: Editorial Librería Ediciones del profesional Ltda.

Peyrano, J. (1997). Compendio de reglas procesales en lo civil y comercial. ( $2^{a}$ ed.). Rosario: Editorial Zeus.

Presidencia de la República. (Septiembre 21 de 1970). Decreto 1400 de 1970. "Por medio del cual se expide el Código de Procedimiento Civil". Diario Oficial n. ${ }^{\circ} 33.150$.

Pulecio, D. (2012a). La teoría de la carga dinámica de la prueba en materia penal: Análisis jurisprudencial. Bogotá: Pontificia Universidad Javeriana, Facultad de Ciencias Jurídicas y Grupo Editorial Ibáñez. 
Pulecio, D. (2012b). La teoría de la carga diná- Tirado, J. (2006). Curso de pruebas judiciales. mica de la prueba en materia penal: análisis jurisprudencial. Revista del Instituto ColomParte General. Tomo I. Bogotá: Ediciones biano de Derecho Procesal, 38, 259-300.

Rosemberg, L. (1955). Tratado de Derecho Procesal. Á. Romera Vera (Trad.). Buenos Aires: Ediciones Jurídicas Europa-América (EJEA). 